\title{
A Generic Approach to Model and Analyze Industrial Search Processes
}

\author{
Philipp Steenwerth ${ }^{(凶)}$ and Hermann Lödding \\ Hamburg University of Technology, Hamburg, Germany \\ \{philipp.steenwerth, loedding\} @tuhh. de
}

\begin{abstract}
Search processes are omnipresent. In the field of industrial production they occur whenever material or information is needed. While searching is a fundamental activity within production processes, existing models and methods in the field of production management are not designed for modelling or analyzing industrial search processes. This paper presents a generic phase model that can be used to describe industrial search processes. Furthermore, an analysis method is proposed to determine and prioritize fields of action for the optimization of search processes.
\end{abstract}

Keywords: Search process, Manufacturing, Generic model, Analysis method.

\section{Introduction}

Manufacturing companies continuously focus on increasing productivity by optimizing their processes [1]. Searching is a fundamental activity of every process since it always occurs when a demand for material or information is present. A general understanding is the basis for designing and optimizing search processes. Since searching does not add value to a product, the reduction of searching in existing processes provides potential for further improvements [2]. Even though some methods, for example in the field of lean production [3], already aim at reducing search processes with standardized tools, a deeper understanding of searching is still missing. For a systematic improvement, a better understanding of the process and the characteristics of searching in the field of industrial production is needed.

This paper presents a generic phase model, which allows to describe industrial search processes. Furthermore, an analysis method that uses the generic phase model to identify potential fields of action for the improvement of search processes is presented.

\section{Search processes in the field of industrial production}

In the field of industrial production, search processes occur whenever materials, tools or information are needed for a job. They are relevant if employees spend significant time on searching or if an item or information cannot be found. Searching reduces labor 
productivity because search activities consume resources without adding value to the product [3].

Nevertheless, searching is a fundamental activity that cannot be avoided completely as it occurs with every demand for material or information. Therefore, it is necessary to analyze and improve search processes to reduce search activities to a minimum.

Productivity analyses show that the procurement of information and material is a significant part of the paid working time, especially in one-of-a-kind production (Figure 1) $[4]$.

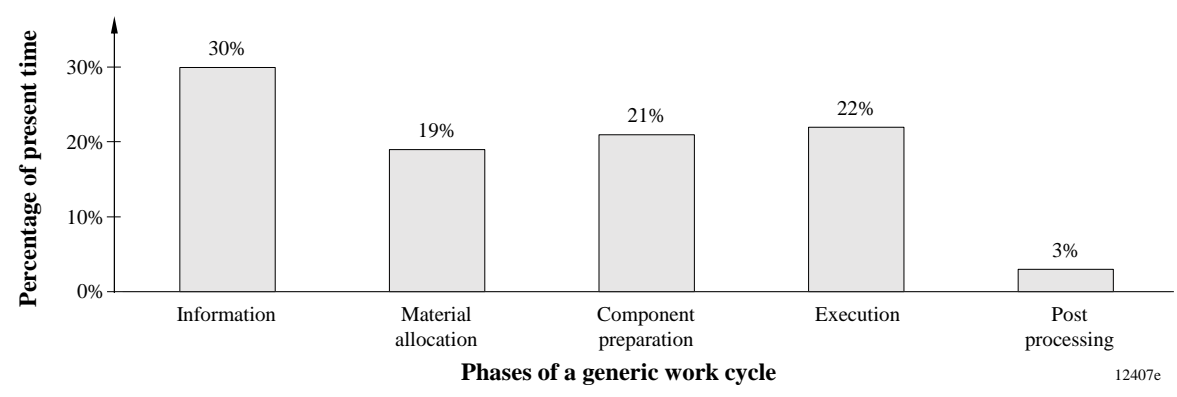

Fig. 1. Working time proportions in shipbuilding production (about 11,000 records in 12 areas of 4 companies, unrecorded time: 5\%) [4]

Even though it is not possible to explicitly identify the proportion of searches from the analysis, it becomes clear from the collected data that searching for information, materials, and tools can be a very important topic for companies. This is especially true if material or information is not easily accessible. The trend towards a greater diversity of variants increases the importance of industrial search processes because it increases the variety of different search objects.

\subsection{Identifying search processes}

Despite the relevance of searching, common approaches in the field of production management do not specifically focus on search activities. The REFA (Association for Work Design, Industrial Organization and Corporate Development) classification, for instance, allows to divide working time into procedures to analyze worker activities [5]. However, explicit assignment of search activities to one specific procedure is unfeasible since the searching process often includes various activities from different procedures.

Predetermined motion time systems are another common methodology used for describing work processes with MTM (Methods-Time Measurement) as the best known representative. They subdivide workflows into work elements to which time durations are assigned. However, occurring search activities are not considered in particular [6].

The classification of work contents in value adding and waste, following the Toyota Production System, is another approach to describe the elements of work [7]. However, searching is not defined as a separate category. 
Within the field of material allocation, search processes are described as separate activities. The activity of searching for objects is assigned to the process of order picking and is classified as downtime [8]. However, downtime is measured as one value and additionally includes other activities therefor.

In summary, the analysis of common approaches outlines that research and practice in production management agree on the fact that search activities can be indicated as waste and should be reduced [2]. However, a model or method that is capable to describe and analyze industrial search processes in general is still missing.

\subsection{Improving search processes}

Even though search processes are not considered separately within the field of lean production, methods that help to reduce searching efforts exist. One of these is the $5 \mathrm{~S}$ method [3], which improves the placement of materials and tools at the workplace. Another method is Visual Management [9], which helps to identify materials and tools more quickly and to make the right information accessible. One problem with using these methods is that their effect on productivity is unclear before they are implemented because the duration of the search process is unknown. Furthermore, the effectivity of a method is hard to quantify since there is no method to compare search processes in general.

Also, the increasing trend of digitalization provides additional tools to reduce and eliminate search activities. One example is the RFID technology, which can be used to keep information about the location of material updated and to make this information easily accessible.

\section{$3 \quad$ Modelling industrial search processes}

Figure 2 shows the generic phase model we propose as a means to describe and compare industrial search processes.

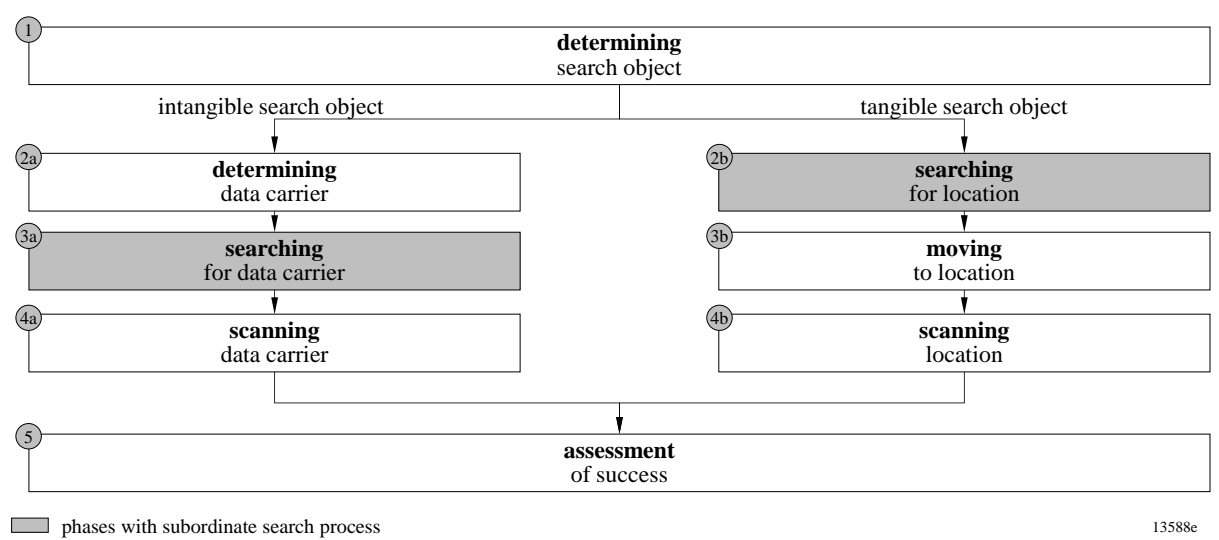

Fig. 2. Generic phase model for industrial search processes 
The model uses five generic phases to describe and compare search processes within the field of industrial production. The phases are described in the following.

Determining search object (1): The first phase of every search process is triggered by the need for a physical object or an information. Search objects can be classified as tangible and intangible. Tangible search objects include tools, material and persons. Intangible search objects can generally be referred to as information. Important information in industrial processes are for example dimensions or process parameters.

The following phases depend on the search object. For intangible search objects, the phases are defined as determining data carrier, searching for data carrier, and scanning data carrier. For tangible objects, the phases are searching for location, moving to location and scanning location. The phases for the information search are described by the example of a required dimension.

Determining data carrier (2a): For intangible search objects, this phase contains the activities that aim at determining the data carrier on which the required information is stored. For the dimension, this could be a 2D paper drawing.

Searching for data carrier (3a): Once the data carrier is defined, all activities that are necessary to get access to the data carrier are included in this phase. For the 2D drawing, the location where the drawing is stored needs to be found.

Scanning data carrier (4a): As soon as the data carrier is accessible, it can be scanned for the required information. This includes all activities that are necessary to gather information from the data carrier. Reading the 2D drawing is one example.

In comparison, the phases for the material search are described by the example of a required screwdriver.

Searching for location (2b): Once a tangible search object is defined, information about possible locations is necessary. All activities that are necessary to get this information belong to this phase. Since the screwdriver is usually in a toolbox at another workstation, this could be the first location to search.

Moving to location (3b): A defined location is the basis for this phase, including all activities necessary to get to the location.

Scanning location (4b): As soon as the location is reached, the scanning for the search object starts. This includes all activities necessary to examine the location for the object, which in our example is a screwdriver.

Every search process, independent of the material constitution of the search object, ends with the last phase of the model, the assessment of success.

Assessment of success (5): By comparing the defined characteristics with the characteristics of a found search object, the success of the search can be assessed. The decisive question is, whether or not the object is found at an estimated place or on an estimated data carrier.

The model outlines that a search process can contain other searches. The search for a tangible object always contains a search for information about the location (intangible object). Vice versa, the search for information always includes the search for the data carrier (physical object). This connection is represented in the model by the two searching phases $(3 \mathrm{a} / 2 \mathrm{~b})$. By this logic, the model is able to describe complex search processes. 
Generally, the total time required to find a search object is an important characteristic of search processes. Similar to the throughput time of production processes [10, 11], a search throughput time can be defined, which comprises the time from the beginning to the end of the search (Figure 3). Following this logic, the search throughput time of a main search process as well as of every subordinate search process can be divided into elements that represent the generic phases. Figure 3 shows a schematic example of a search process for information (intangible search object) in level 1, with a subordinate search process for a data carrier (tangible search object) in level 2. The data carrier that is determined in the first search process is at the same time the search object for the subordinate search process in level 2. Hence, the first phase of the model (determining the search object) does not occur in subordinate search processes.

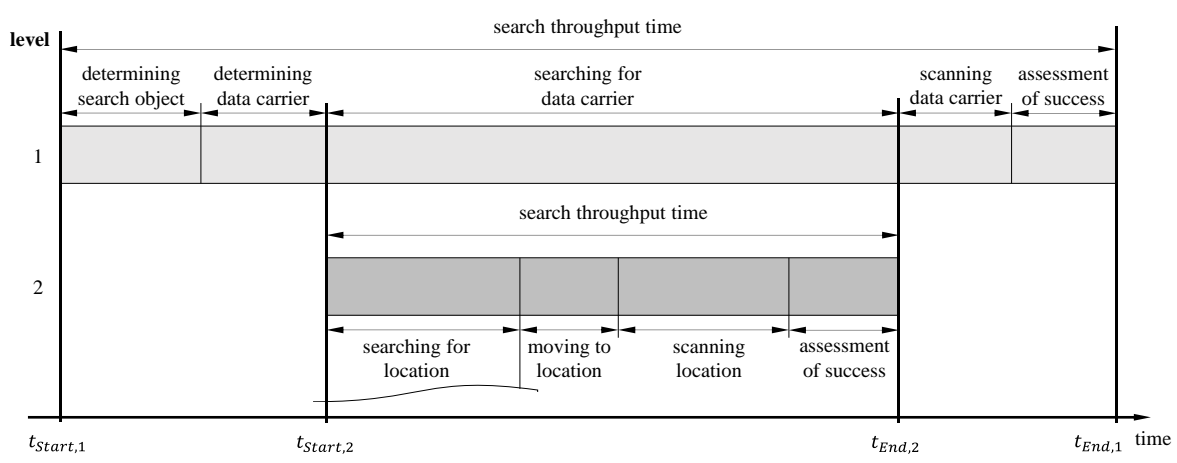

Fig. 3. Concept of search lead time with a main search process for intangible search objects

\section{$4 \quad$ Analyzing industrial search processes}

The phase model for search processes can be used to identify and evaluate industrial search processes. Therefore, a method was developed that is structured in the three steps data collection, data aggregation, and data analysis.

\subsection{Data collection}

Initially, data regarding the search processes needs to be collected. A feasible method is to follow a worker during a whole search process to measure the time spent in each phase. Since some activities of searching are hard to observe, it is essential that the worker comments his activities while searching. By this method, cognitive activities, like determining the search object, can be observed, as well as physical activities like moving to a location. It is essential to gather information about the allocation of search efforts to subordinate search processes.

A web-based application for productivity analyses (CheckIT) [12] was customized to support the process of data collection. The analysis starts with the classification of the actual search object, followed by a hierarchical query of a generic phase to track 
subordinate search processes. The time for a selected phase is tracked automatically until the next phase is selected.

\subsection{Data aggregation}

Accordingly, the collected data is aggregated with respect to the generic phases. The output of the data acquisition can be aggregated for the main search process and for all subordinate search processes. In order to distinguish the individual processes, levels are introduced. If necessary, the model allows to go through every phase several times within one search process. This could, for example, be the case if another location is scanned after a tangible object was not found at the first location. The search process for one search object is related to one level, beginning with the main search process. The total length of a phase equals the sum of all measured times for the phase within the same level. The sum of all phases of the same level equals the search throughput time (see Figure 3) for this level.

For intangible objects: $S T T P_{i}=\sum d s_{i}+\sum d c_{i}+\sum s c_{i}+\sum s d_{i}+\sum a s_{i}$

For tangible objects: $S T T P_{i}=\sum d s_{i}+\sum s f l_{i}+\sum m l_{i}+\sum s l_{i}+\sum a s_{i}$

With: $\operatorname{STTP}_{i}$ search throughput time $d s_{i} \quad$ determining search object $d c_{i} \quad$ determining data carrier $s c_{i} \quad$ searching for data carrier $s d_{i} \quad$ scanning for data carrier

$$
\begin{array}{ll}
a s_{i} & \text { assessment of success } \\
s f l_{i} & \text { searching for location } \\
m l_{i} & \text { moving to location } \\
s l_{i} & \text { scanning location } \\
i & \text { level of search process }
\end{array}
$$

Additionally, the total length of a search phase $(3 a / 2 b)$ within one level equals the search throughput time of the according subordinate search process $\left(S T T P_{i+1}\right)$.

$$
\begin{aligned}
\sum s c_{i} & =S T T P_{i+1} \\
\sum s f l_{i} & =S T T P_{i+1}
\end{aligned}
$$

\subsection{Data analysis}

The analysis includes the processing and visualization of data in key figures. This allows to gain a deeper understanding of existing search processes and to identify fields of potential as a basis for improvements. The main results of the analysis are:

- The given structure of the search process: The hierarchical aggregation of search phases illustrates the relations between all subordinate search processes that are observed. Thus, a deeper understanding of existing search processes is provided

- Identification and prioritization of the greatest field of action: By the portions of each phase in every search process a prioritization can derived with regard to the potential for improvement. 


\section{$5 \quad$ Evaluation by a simplified application}

The model and the analysis method were tested in an experimental environment with 7 test persons to evaluate the usability. The experiment included a manufacturing task, in which a case cover needs to be found. To support the search process, the test persons were given a document with possible locations of the missing workpiece.

Every test person was observed during the entire search process and the time spent in every phase was measured using the analysis method. During the whole experiment, the test persons were encouraged to comment their thoughts.

The results are shown in Figure 4. All calculated numbers represent mean durations. As it can be seen, the observed search process consists of two levels, the main search for the case cover (tangible search object) and one subordinate search process for information about the location (intangible search object). The average search lead time for the case cover is 87.5 seconds, including 33.5 seconds for searching for the location (subordinate search process). Within the information search, only the phase of scanning the data carrier was observable. This is probably because the document was already handed out to the test persons in the beginning of the experiment. Overall, the scanning of the data carrier was the most time consuming phase of the entire search and is therefore a potential starting point for improvements.

The experiment also shows that some phases can be marginal up to a degree, where it becomes difficult to observe and measure a meaningful time duration. In the experiment, this is the case for all phases of the search process for the data carrier except the scanning phase.

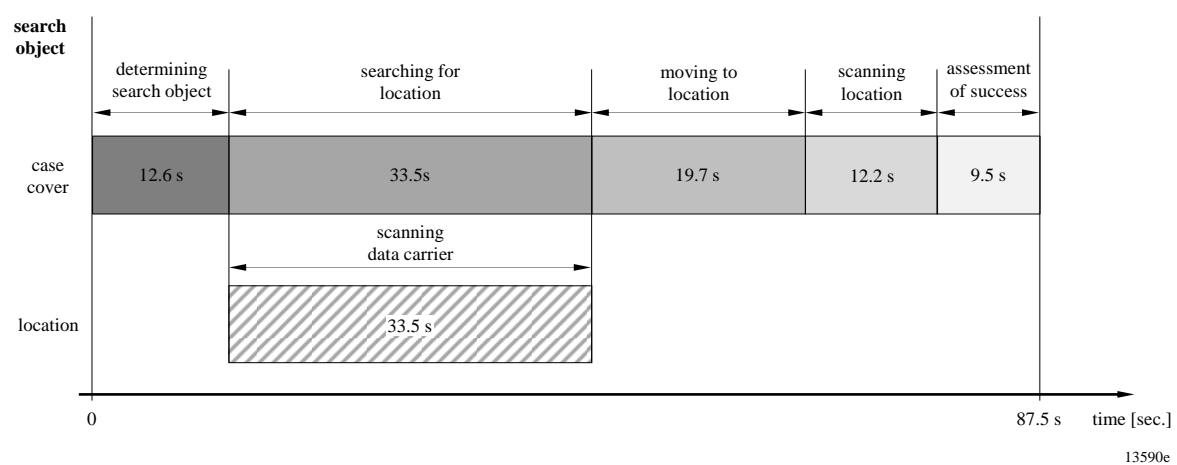

Fig. 4. Results of experimental analysis (mean duration, $n=7$ )

\section{$6 \quad$ Summary and Outlook}

The presented model is designed to comprehensively describe industrial search processes. Subordinate search processes allow to model complex, multi-level search processes. With the presented analysis method, search processes of industrial processes can be identified and evaluated. In future research, it is intended to use the approach on 
a larger scale. One idea is to combine the time durations from the analysis with information about the total number of search objects of the same class to estimate the aggregate search effort. The goal is to gain knowledge about existing search processes and to calculate an overall potential for improvements within a company.

Acknowledgement. The Authors would like to thank Deutsche Forschungsgesellschaft (DFG) for funding the project "Analysis and optimization of searching procedures in manufacturing environments" (Project No. 365697984).

\section{References}

1. Czumanski, T., Lödding, H.: Analyse von Einflussfaktoren auf die Arbeitsproduktivität in der Serienproduktion. In: Müller, E. (ed.) Demographischer Wandel-Herausforderung für die Arbeits- und Betriebsorganisation der Zukunft, pp. 237-261. GITO-Verlag, Berlin (2012).

2. Liker, J.: The Toyota Way: 14 Management Principles from the World's Greatest Manufacturer. McGraw-Hill, New York (2004).

3. Hirano, H.: JIT implementation manual: The complete guide to just-in-time manufacturing, 2nd edn. Waste and the 5S's, vol 2. CRC Press, Boca Raton, Fl. (2009).

4. Tietze, F., Lödding, H.: Analyse der Arbeitsproduktivität in der Unikatfertigung: Eine Grundlage für zielorientierte Verbesserungsprozesse in der Unikatfertigung. Industrie Management 30(3): 62-66 (2014).

5. REFA: Datenermittlung. Methodenlehre der Betriebsorganisation, vol 15. Carl Hanser Verlag, München (1997).

6. Bokranz, R., Landau, K.: Produktivitätsmanagement von Arbeitssystemen: MTMHandbuch. Schäffer-Poeschel, Stuttgart (2006).

7. Ohno, T.: Toyota production system: Beyond large-scale production. Productivity Press, Cambridge, Mass. (1988).

8. Hompel, M., Sadowsky, V., Beck, M.: Kommissionierung: Materialflusssysteme 2 - Planung und Berechnung der Kommissionierung in der Logistik. Springer, Berlin (2011).

9. Takeda, H.: The synchronized production system: Going beyond just-in-time through Kaizen. Kogan Page, London (2006).

10. Wiendahl, H.-P.: Betriebsorganisation für Ingenieure, 7th edn. Hanser, München (2010).

11. Bechte, W.: Steuerung der Durchlaufzeit durch belastungsorientierte Auftragsfreigabe bei Werkstattfertigung. Fortschritt-Berichte der VDI-Zeitschriften 2(70) (1984).

12. Grabner, C., Khokhar, F., Schoop, T. et al.: Ein digitales Universalwerkzeug für die Produktionsanalyse: Entwicklung einer Web-App zur methodenübergreifenden Analyse von Produktionsprozessen. Industrie Management(6): 7-10 (2017). 